\title{
Design of a Portable Demonstration Unit of Solar Power Systems for Analog Electronics Courses
}

\section{Prof. Yoon Kim, Calvin College}

Yoon G. Kim received his M.S. and D.Sc. degrees in Electrical Engineering from Washington University in St. Louis in 2000 and 2005, respectively. He is a faculty member of the Electrical and Computer Engineering program in the Engineering Department at Calvin College in Michigan and teaches courses in analog electronics and control systems. He has over 11 years of industrial Research and Development experience in the area of telecommunication systems, where he designed analog and digital systems, including digital set-top-box converters for Hybrid Fiber Coax cable networks, digital video scramblers, data acquisition systems, analog subscriber line interface systems, DC-DC converters, DC-AC converters, and microprocessor boards. His research interests include Wireless Sensor Networks, Power Electronics and Embedded Systems.

Shurjo Maitra, Calvin College 


\title{
Design of a portable demonstration unit of solar power systems for analog electronics courses
}

\begin{abstract}
This paper presents a practical approach to improving the knowledge and awareness of solar power systems by using a demonstration unit in an analog electronics course. The unit aids instructors in teaching an introductory-level laboratory experiment focused on solar power harvesting and storage and enables instructors to bring in a functional system into labs or classrooms for upper-class undergraduate electrical and computer engineering students. The unit can be used to demonstrate many of the aspects of solar power systems, helping instructors address sustainability and renewable energy issues.
\end{abstract}

Solar power systems based on photovoltaic (PV) cells have been successfully deployed as renewable energy sources. They have become one of the promising technologies, providing a sustainable energy source as many natural resources are depleting. Due to the importance and wide acceptance of this technology, a demonstration unit has been developed to introduce solar power systems to students at various stages in their education.

The approach to improving the students' knowledge of solar power systems is to integrate students' knowledge and experiences with basic electric circuits acquired from their first electronics course and to enhance their learning about new technologies through hands-on experiments in labs or classroom demonstrations. The unit would help students better understand renewable energy by teaching them how to obtain environment-friendly energy from sunlight. It will provide students with an opportunity to apply their knowledge in science and technology to solve a real-world problem.

The unit includes a custom-designed light fixture consisting of thirty (30) high-power LEDs as an optical energy source, two 1-watt solar panels as the energy harvesting devices, a fixture for adjusting the solar panel angle, a battery charge controller, voltage and current meters for measuring power, a variable resistor and switches for measuring the I-V characteristics of the panel, and a sealed lead-acid battery as energy storage. The overall size of the unit is $21 \times 17$ inches $(533.4 \times 431.8 \mathrm{~mm})$ and it would be setup at students' lab stations or on a cart for the instructor in a class. It would enable any instructor to easily adopt the solar power demonstration unit as a lab and classroom instrument in their analog circuit courses. This paper includes a complete wiring diagram, part numbers and vendor lists, procedures for experiments and demonstration, and measurement data.

After all lab experiments have been completed, the students submit a lab report, which includes objectives, results/discussion, and conclusions. All twenty-one junior students have successfully completed the lab. The survey results have shown that they found the lab and demonstration unit beneficial in their understanding of solar power systems. 


\section{Introduction}

The acceptance of photovoltaic cells as energy harvesting devices has been growing as they provide reliable electricity without noise or moving parts ${ }^{1}$. Once installed, solar power systems using photovoltaic cells provide an alternative energy source that does not produce $\mathrm{CO} 2$ gas.

Due to the widely accepted technology, many higher education institutions have been including solar cell laboratories and lectures in their power electronics courses ${ }^{2}$. Four different types of solar cells were used in a renewal energy course ${ }^{3}$. Photovoltaic training systems were developed to provide hands-on experiments for engineering technology programs ${ }^{4,5}$.

In this paper, a practical approach to teaching an introductory-level lab experiment on solar power systems for indoor is presented. The lab experiments have been included in a junior level analog electronics course as a lab component. The target students were junior electrical and computer engineering students who had completed a course on basic electric circuits.

The approach is to integrate students' prior knowledge and experiences with basic electric circuits -current and voltage measurements, power calculation, Ohm's law, and Kirchhoff's current/voltage law and to introduce solar power systems utilizing a portable demonstration unit in labs or classrooms, where the experiments described in Section 6 can be conducted. The students can easily test the solar power systems by changing the positions of three switches and by reading the current and voltage meters on the unit. The experimental procedures are designed to not only improve students' understanding of the material, but also enable students to conduct the experiments in a step-by-step fashion.

The background information was covered at the beginning of lab and it was reinforced by experiments and measurements during the lab.

\section{Educational Objectives}

The educational objectives of the Portable Solar Power Demonstration Unit are:

- To understand that solar power systems are comprised of four major components (a solar panel, solar power/charge controller, battery, and load),

- To comprehend the unique functions of the major components of the unit,

- To understand the critical parameters of the solar panel,

- To figure out how to adjust the angle of the solar panel to maximize the open circuit voltage,

- To know how to monitor the level of charge on a battery,

- To know how to safely measure currents and voltages on the input and output stages,

- To be able to compute the maximum power generated by the solar panel, and

- To be able to compare the measurements on real circuitry with the specifications found in a datasheet. 
Students will learn how to obtain renewable energy from sunlight and how to store it. Utilizing the unit will provide students with an opportunity to apply their prior knowledge and experience with fundamental electric circuits to address a real-world problem.

\section{Main components and Bill of Materials}

The demonstration unit is shown in Figure 1. The main components of the unit and the corresponding bill of materials are listed in Table 1. Many of the components of the unit listed in Table 1 are mounted on the board whose size is 21 x 17 inches. The unit includes two sets of voltage and current meters, one set of each is placed at the output of the solar panel and one at the battery, simplifying the measurements. The solar panel fixture allows a user to adjust the angle of the panel facing the light fixture. This feature helps students understand that the angle affects the output power of the panel. To obtain the maximum power, the panel should be parallel with the light fixture. A low-voltage (min. 2.9 V) and high-current (min. 10.5 A) DC power supply is needed to properly operate the LED light fixture, which is comprised of thirty (30) high-power white LEDs ${ }^{6,7}$. Each LED requires a voltage in the range of $2.9 \mathrm{~V}$ to $3.5 \mathrm{~V}$ and a current in the range of $0.35 \mathrm{~A}$ to $1.0 \mathrm{~A}$. For the LED fixture we used the DC power supply listed in Table 1, which provided $3.1 \mathrm{~V}$ and 20.0 A.

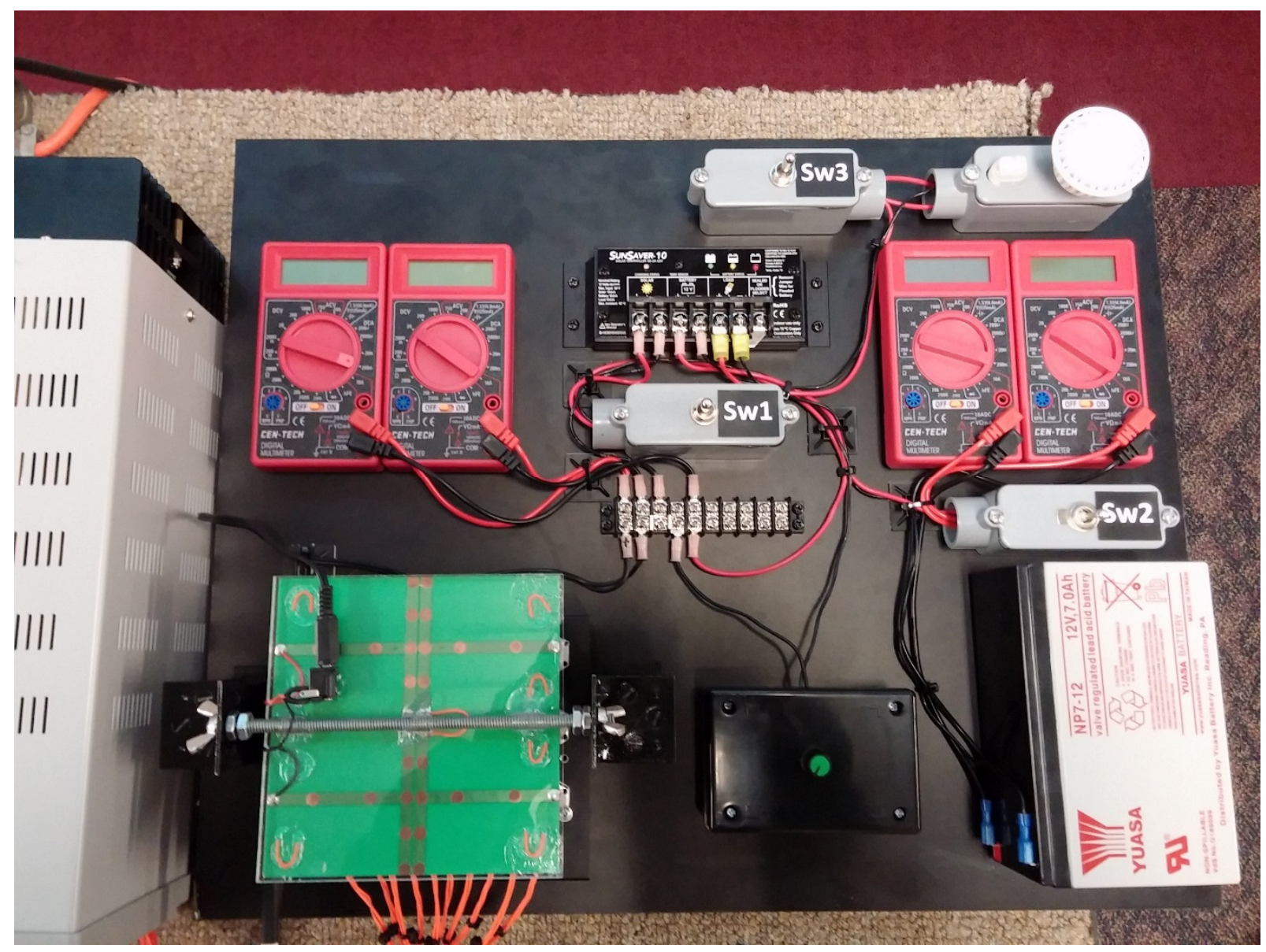

Figure 1: Demonstration unit of solar power systems 
Note that the LED light fixture and solar panel fixture are custom-designed components built at Calvin College. The remaining components are easily available.

Table 1: Main components and bill of materials

\begin{tabular}{|c|c|c|}
\hline Description & Item Number & Qnty \\
\hline DC Power Supply, $30 \mathrm{~V}, 20 \mathrm{~A}$ & "HY3020D (MASTECH) & 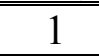 \\
\hline $\begin{array}{l}\text { Solar Panel6 V@1 W, } 125 \text { x 63mm (Mono-Crystalline } \\
\text { Silicon) }\end{array}$ & 619-750-00030 (Mouser) & 2 \\
\hline SunSaver PV System Controller, 12 V, 10 A & SS-10-12V (Morningstar) & 1 \\
\hline 12 V Sealed Lead Acid Battery, 7 Ah & NP7-12 F2 (YUASA) & 1 \\
\hline $\begin{array}{l}\text { LED Light Fixture (with } 30 \text { high-power warm white } \\
\text { LEDs }^{6} \text { ) }\end{array}$ & $\begin{array}{l}\text { Custom-built at Calvin } \\
\text { College }\end{array}$ & 1 \\
\hline Solar Panel Fixture (feature with adjustable angle) & $\begin{array}{l}\text { Custom-built at Calvin } \\
\text { College }\end{array}$ & 1 \\
\hline Potentiometer, $10 \mathrm{k} \Omega, 1 \mathrm{~W}$, Single-turn & 6639S-1-103-ND (Digikey) & 1 \\
\hline 7 Function Digital Multimeter & $\begin{array}{l}90899 \text { (Harbor Freight } \\
\text { Tools) }\end{array}$ & 4 \\
\hline $\begin{array}{l}\text { Utilitech } 20 \text { W Equivalent Warm White Wedge LED } \\
\text { Decorative Light Bulb }\end{array}$ & 596947 (Lowe's) & 1 \\
\hline $\begin{array}{l}\text { SYLVANIA } 50 \text { W Equivalent Dimmable Warm White } \\
\text { MR16 LED Flood Light Bulb }\end{array}$ & 783534 (Lowe’s) & 1 \\
\hline $\begin{array}{l}\text { SERVALITE Single Pole Silver Metallic Light Switch } \\
\text { (on-off-on) }\end{array}$ & 543137 (Lowe’s) & 2 \\
\hline SERVALITE Single Pole Black Light Switch (on-on) & 75706 (Lowe's) & 1 \\
\hline CARLON 1/2-in PVC Transition Conduit & 75783 (Lowe’s) & 4 \\
\hline The Hillman Group 1/4-in x 6-in Threaded Rod & 424643 (Lowe's) & 1 \\
\hline $\begin{array}{l}\text { The Hillman Group 2-Count 1/4-in Stainless Steel } \\
\text { Standard (SAE) Forged Wing Nuts }\end{array}$ & 136135 (Lowe's) & 2 \\
\hline $\begin{array}{l}\text { Stanley-National Hardware 1.5-in Metallic Corner } \\
\text { Brace }\end{array}$ & 66938 (Lowe’s) & 2 \\
\hline VELCRO 2-in x 4-in Black Rectangle Fastener & 46238 (Lowe's) & 2 \\
\hline
\end{tabular}

\section{Implementation}

The overall wiring diagram of the demonstration unit is shown in Figure 2. In general, solar power systems based on photovoltaic cells have four functional blocks: a solar cell panel (energy harvester), a solar power controller (battery charger), a battery (energy storage), and a load (energy consumer). To conduct experiments for each block in a lab or demonstrate the functionality of the solar power system in a class, the unit has four (4) switches to route the connections between the functional blocks. There are five primary modes for demonstrating the functionality of each block of the demonstration unit. They are listed in Table 2. 


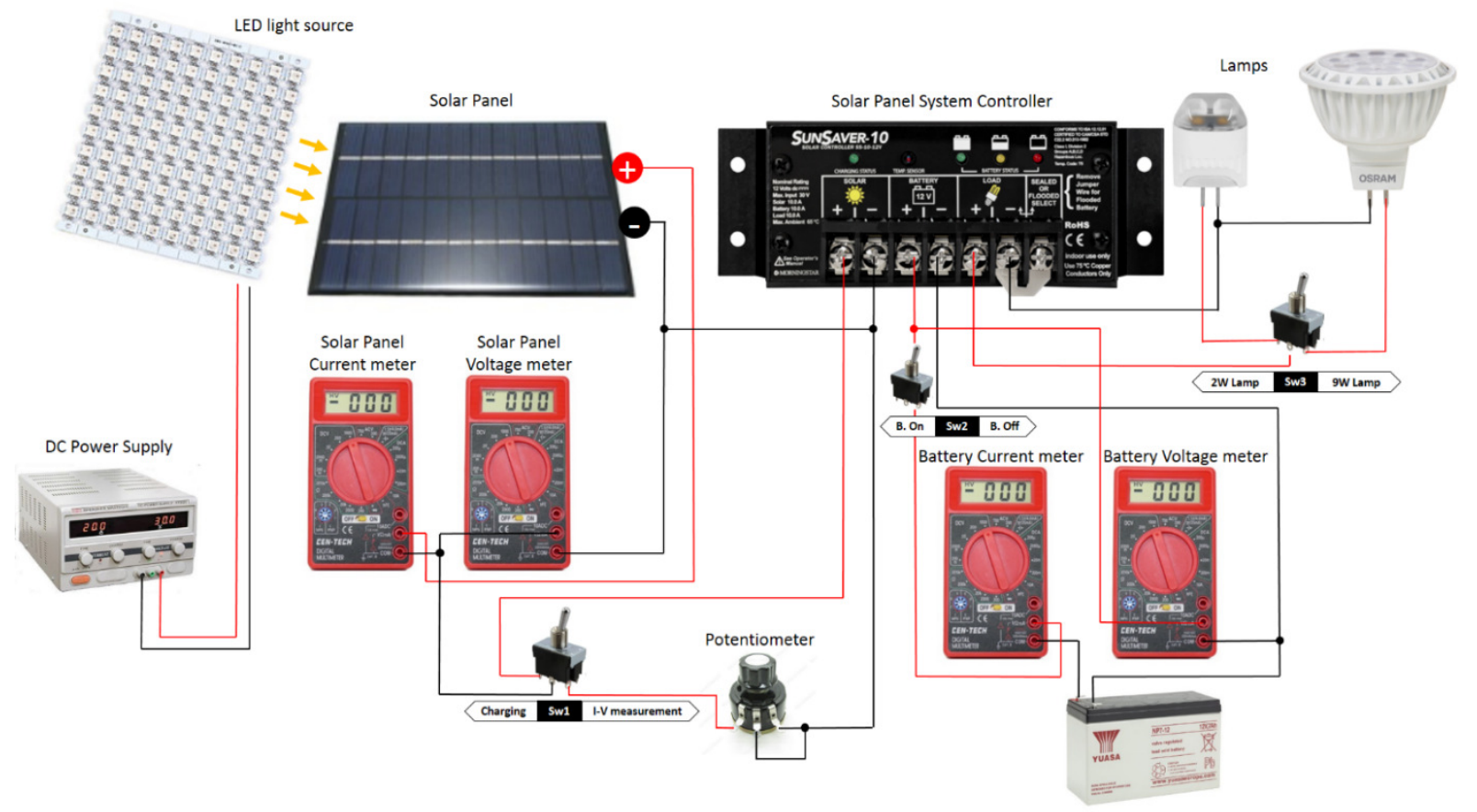

Figure 2: System Wiring Diagram of Demonstration unit

Table 2: Mode for demonstrating the functionality of the unit

\begin{tabular}{|c|c|c|c|c|}
\hline \multirow{2}{*}{ Mode } & \multicolumn{3}{|c|}{ Switch Position } & Remark \\
\cline { 2 - 5 } & Sw1 & Sw2 & Sw3 & \\
\hline Measuring Open Circuit Voltage & Center & Right & Center & \\
\hline Measuring Short Circuit Current & Right & Right & Center & Variable resistor: 0 $\Omega$ \\
\hline Charging Battery & Left & Left & Center & \\
\hline Discharging Battery & Center & Left & Left & For a 2 W bulb \\
\hline Measuring I-V Characteristics & Right & Right & Center & \\
\hline
\end{tabular}

Figure 3 shows the solar panel fixture (top piece) where the angle facing the LED light fixture can be adjusted. The LEDs of the light fixture are mounted on an aluminum heatsink. An additional cooling fan was installed next to the heatsink to improve heat dissipation.
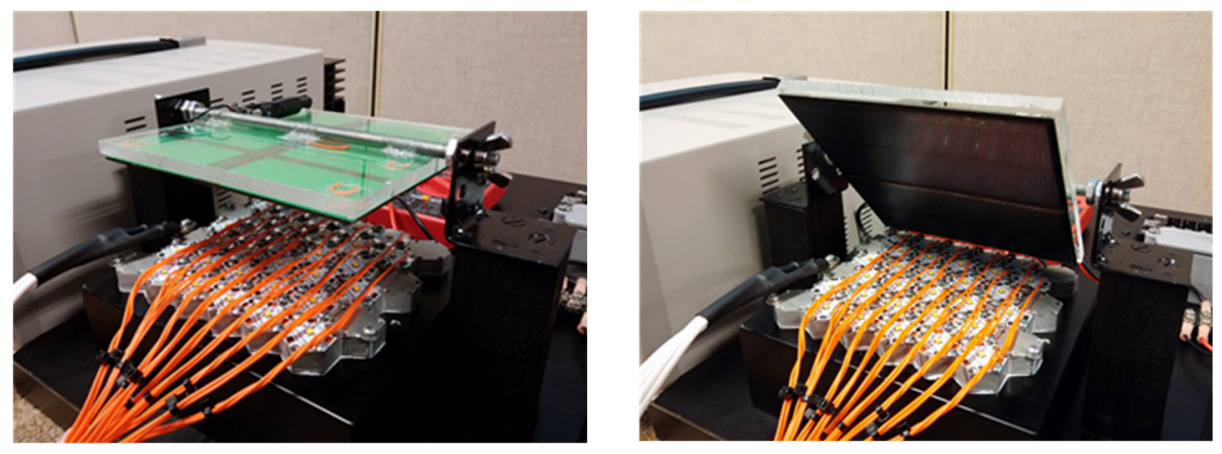

Figure 3: Solar panel fixture and LED light fixture 


\section{I-V characteristics of the solar panel}

A solar panel is comprised of multiple PV cells in which each cell has its own current vs. voltage characteristics. The maximum power generated by a solar panel is one of the key specifications of a solar panel. It can be calculated from measured currents and voltages under the irradiance of $1000 \mathrm{~W} / \mathrm{m}^{2}$, which is the normal irradiance at sea level. The described LED light fixture generates approximately $600 \mathrm{~W} / \mathrm{m}^{2}$ as measured by a solar power meter ${ }^{9}$. Operating at this level, the measurements of current and voltage of the solar panel are listed in Table 3 . The values were taken while varying the resistance of a power potentiometer attached to the panel. The solid blue line in Figure 4 shows the I-V characteristic curve generated by the measured currents and voltages shown in Table 3. The red dashed line shows the calculated power as a function of voltage.

Table 3: Measured output currents and voltages of solar panel

\begin{tabular}{|r|r|r|r|}
\hline Current [mA] & Voltage [V] & $\begin{array}{c}\text { Calculated } \\
\text { Resistance }[\Omega]\end{array}$ & $\begin{array}{c}\text { Output Power } \\
{[\mathrm{mW}]}\end{array}$ \\
\hline 1.00 & 14.00 & 9835 & 19 \\
\hline 1.53 & 13.65 & 8922 & 21 \\
\hline 1.72 & 13.65 & 7936 & 23 \\
\hline 1.96 & 13.64 & 6959 & 27 \\
\hline 2.28 & 13.63 & 5978 & 31 \\
\hline 2.73 & 13.62 & 4989 & 37 \\
\hline 3.41 & 13.60 & 3988 & 46 \\
\hline 4.53 & 13.58 & 2998 & 62 \\
\hline 6.78 & 13.54 & 1997 & 92 \\
\hline 13.39 & 13.41 & 1001 & 180 \\
\hline 14.83 & 13.38 & 902 & 198 \\
\hline 16.63 & 13.34 & 802 & 222 \\
\hline 18.90 & 13.28 & 703 & 251 \\
\hline 21.89 & 13.19 & 603 & 289 \\
\hline 25.92 & 13.02 & 502 & 337 \\
\hline 31.59 & 12.70 & 402 & 401 \\
\hline 39.97 & 12.07 & 302 & 482 \\
\hline 47.75 & 9.65 & 202 & 461 \\
\hline 48.64 & 4.97 & 102 & 242 \\
\hline 48.95 & 4.54 & 93 & 222 \\
\hline 49.08 & 4.07 & 83 & 200 \\
\hline 51.70 & 0.11 & 2 & 6 \\
\hline & & & \\
\hline
\end{tabular}

The solar panel was parallel to the LED array, at a distance of 1.85 inches, when the data in the table was taken. As found in the table, the maximum power generated by the solar panel is approximately $482 \mathrm{~mW}$. The maximum power point is also shown in Figure 4, where the value of voltage is $12.07 \mathrm{~V}$ and the value of current is $39.97 \mathrm{~mA}$. The fill factor (FF) of a solar panel measures the performance of the panel. It can be calculated by the following equation ${ }^{1}$. 
Fill Factor $=\frac{V_{\text {max. power }} I_{\text {max.power }}}{V_{\text {open-circuit }} I_{\text {short-circuit }}} \times 100 \%=\frac{(12.7 \mathrm{~V})(39.97 \mathrm{~mA})}{(14.0 \mathrm{~V})(51.70 \mathrm{~mA})} \times 100 \%=70.13 \%$

\section{I-V Characteristics}

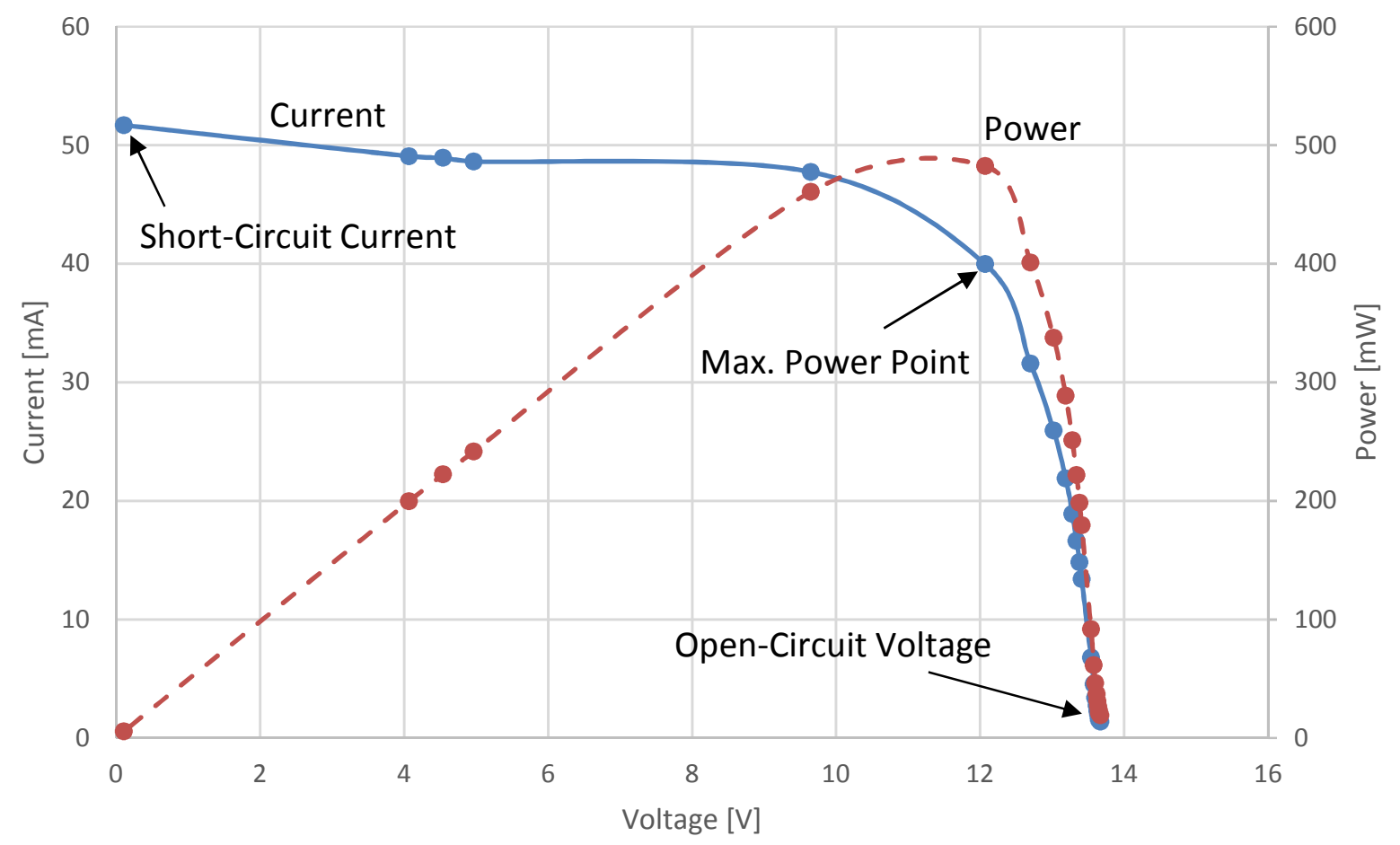

Figure 4: I-V Characteristics of solar panel (Measured)

\section{Details of Laboratory Experiment}

As an introductory-level solar power systems lab, the unit includes essential components to demonstrate the basic functionality of solar power systems. The following step-by-step procedures were provided to the students to improve their understanding of the lab and to help them conduct effective experiments.

\section{Procedure:}

Note: Turn on the DC power supply only when reading the current and voltage meters. Any user must wear safety glasses with filter lenses for protection from light radiation ${ }^{10}$.

\section{Review Circuits}

1) Understand the overall system wiring diagram (Figure 2). When the solar panel provides enough power to the controller, the current flows into the battery to store energy. When there is no energy generated by the panel (e.g., at night), the controller stops charging. At 
night the stored energy can be used by an LED bulb where the current flows from the battery to the load.

\section{System Check}

2) Turn on the DC power supply to generate optical energy through the LED light fixture. The fixture acts as a solar ray generator. Turn off the supply after you confirm the white light is emitting from the fixture.

3) Check the solar input wiring and its polarity in Figure 2. The solar system controller has three ports to connect a solar panel, battery, and load. Make sure that the polarity is correct.

4) Check the battery wiring and its polarity as shown in Figure 2. The battery stores the energy harvested from the solar panel. The controller utilizes pulse-width modulation (PWM) to charge the battery, based on the level of charge on the battery.

5) Check the load wiring and its polarity as shown in Figure 2. A 2-watt or 9-watt LED bulb can be selected by the user. A 2 -watt LED is equivalent to a 20 -watt incandescent bulb, while a 9 -watt LED is equivalent to a 50 -watt incandescent bulb.

\section{Experimental Steps}

6) Setup the system to measure the open circuit voltage of the solar panel. The open circuit voltage is one of the critical parameters of the panel. Configure the switches in Figure 2 as follows.

\begin{tabular}{|c|c|c|}
\hline Switch Number & Position & Remark \\
\hline \hline Sw1 & Center & Not connected to any circuit \\
\hline Sw2 & Right & Battery is disconnected (off) \\
\hline Sw3 & Center & Not connected to any circuit \\
\hline
\end{tabular}

7) Turn on the DC power supply. Adjust the angle of the solar panel to make it parallel to the light fixture. Also, adjust the location of the light fixture base until the solar panel voltage is maximized, which can be seen on the voltmeter. Read the solar panel current and voltage meters. Fill in the blank. Note that the current should be zero due to the open circuit.

\begin{tabular}{|c|c|}
\hline Solar panel current & Solar panel voltage \\
\hline \hline $00.0[\mathrm{~mA}]$ & (greater than $13.2 \mathrm{~V})[\mathrm{V}]$ \\
\hline
\end{tabular}

8) Setup the system to measure the short circuit current of the solar panel. The short circuit current is one of the critical parameters of the panel. Configure the switches in Figure 2 as follows.

\begin{tabular}{|c|c|c|}
\hline Switch Number & Position & Remark \\
\hline \hline Sw1 & Right & I-V measurement \\
\hline Sw2 & Right & Battery is disconnected (off) \\
\hline Sw3 & Center & Not connected to any circuit \\
\hline
\end{tabular}


Turn the potentiometer counter-clockwise all the way so that it is nearly zero ohms. This shorts out the panel.

9) Read the solar panel current and voltage meters. Fill in the blanks.

\begin{tabular}{|c|c|}
\hline Solar panel current & Solar panel voltage \\
\hline$[\overline{\mathrm{mA}]}$ & (less than $0.5 \mathrm{~V}$ ) [V] \\
\hline
\end{tabular}

10) Setup the system to measure the current consumption of the solar controller. To operate the controller, the solar panel needs to supply current and voltage to the controller. Configure the switches in Figure 2 as follows.

\begin{tabular}{|c|c|c|}
\hline Switch Number & Position & Remark \\
\hline \hline Sw1 & Left & Charging battery \\
\hline Sw2 & Right & Battery is disconnected (off) \\
\hline Sw3 & Center & Not connected to any circuit \\
\hline
\end{tabular}

11) Read the solar panel current and voltage meters. Fill in the blanks.

\begin{tabular}{|c|c|}
\hline Solar panel current & Solar panel voltage \\
\hline$[\mathrm{mA}]$ & [V] \\
\hline
\end{tabular}

12) Setup the system to charge the battery by harvesting energy from the solar panel.

Configure the switches in Figure 2 as follows.

\begin{tabular}{|c|c|c|}
\hline Switch Number & Position & Remark \\
\hline \hline Sw1 & Left & Charging battery \\
\hline Sw2 & Left & Battery is connected (on) \\
\hline Sw3 & Center & Not connected to any circuit \\
\hline
\end{tabular}

13) Read the solar panel current and voltage meters. Fill in the blanks.

\begin{tabular}{|rr|r|}
\hline Solar panel current & Solar panel voltage \\
\hline \hline & {$[\mathrm{mA}]$} & {$[\mathrm{V}]$} \\
\hline
\end{tabular}

14) There are three (3) small LEDs (Green, Yellow, and Red) on the controller that indicate the level of charge on the battery. Keep the DC power supply on until the Green or Yellow indicator stays on solid or flashes slow (1 flash per $2 \mathrm{sec}$ ). Refer to the table below ${ }^{11}$.

\begin{tabular}{|c|c|c|c|}
\hline Batt. Status LED & Indication & Battery Status & Load Status \\
\hline \hline Green & 2 flash per sec. & Equalize Charge & Connected \\
\hline Green & 1 flash per sec. & Absorption Charge & Connected \\
\hline Green & $\mathbf{1}$ flash per 2 sec. & Float Charge & Connected \\
\hline Green & On Solid & Battery Nearly Full & Connected \\
\hline Yellow & On Solid & Battery Half Full & Connected \\
\hline Red & 1 flash per sec. & Battery Low & Connected \\
\hline Red & On Solid & Battery Empty & Disconnected \\
\hline None & No LEDs On & Battery Missing & Disconnected \\
\hline
\end{tabular}


15) Record the battery status LED. Read the solar panel current and voltage meters. Fill in the blanks. Wait for a couple of seconds to give the controller time to start.

\begin{tabular}{|r|r|r|r|}
\hline Batt. Status LED & Indication & Solar panel current & Solar panel voltage \\
\hline \hline & & {$[\mathrm{mA}]$} & {$[\mathrm{V}]$} \\
\hline
\end{tabular}

16) Setup the system to discharge energy from the battery to the load (lamps). Turn off the DC power supply to cut off the light fixture. It emulates the system at night. Configure the switches in Figure 2 as follows.

\begin{tabular}{|c|c|c|}
\hline Switch Number & Position & Remark \\
\hline Sw1 & Center & Not connected to any circuit \\
\hline Sw2 & Left & Battery is connected (on) \\
\hline Sw3 & Left & To turn on 2W bulb \\
\hline
\end{tabular}

17) Read the battery current and voltage meters. Note that the current should be negative, due to the discharge. Fill in the blanks.

\begin{tabular}{|r|r|}
\hline Battery current & Battery voltage \\
\hline \hline$[\mathrm{mA}]$ & {$[\mathrm{V}]$} \\
\hline
\end{tabular}

18) Setup the system to calculate the maximum power generated by the solar panel. The maximum power is one of the critical parameters of the panel. Configure the switches in Figure 2 as follows.

\begin{tabular}{|c|c|c|}
\hline Switch Number & Position & Remark \\
\hline \hline Sw1 & Right & I-V measurement \\
\hline Sw2 & Right & Battery is disconnected (off) \\
\hline Sw3 & Center & Not connected to any circuit \\
\hline
\end{tabular}

19) Turn the potentiometer counter-clockwise all the way to have nearly zero ohm on it. This makes the panel output short. Record the short circuit current in the first row below. Turn the knob a little bit, for example, one tenth of a single-turn angle. Wait for few seconds to find the stable values. Repeat ten times to fill in the blanks.

\begin{tabular}{|r|r|r|}
\hline \multicolumn{1}{|c|}{ Solar panel current } & Solar panel voltage & Power calculated \\
\hline \hline$[\mathrm{mA}]$ & (less than 0.3V) [V] & {$[\mathrm{W}]$} \\
\hline$[\mathrm{mA}]$ & {$[\mathrm{V}]$} & {$[\mathrm{W}]$} \\
\hline$[\mathrm{mA}]$ & {$[\mathrm{V}]$} & {$[\mathrm{W}]$} \\
\hline$[\mathrm{mA}]$ & {$[\mathrm{V}]$} & {$[\mathrm{W}]$} \\
\hline$[\mathrm{mA}]$ & {$[\mathrm{V}]$} & {$[\mathrm{W}]$} \\
\hline$[\mathrm{mA}]$ & {$[\mathrm{V}]$} & {$[\mathrm{W}]$} \\
\hline$[\mathrm{mA}]$ & {$[\mathrm{V}]$} & {$[\mathrm{W}]$} \\
\hline$[\mathrm{mA}]$ & {$[\mathrm{V}]$} & {$[\mathrm{W}]$} \\
\hline$[\mathrm{mA}]$ & {$[\mathrm{V}]$} & {$[\mathrm{W}]$} \\
\hline$[\mathrm{mA}]$ & {$[\mathrm{V}]$} & {$[\mathrm{W}]$} \\
\hline$[\mathrm{mA}]$ & {$[\mathrm{V}]$} & {$[\mathrm{W}]$} \\
\hline
\end{tabular}

20) Find the maximum value in the third column above and enter it in the "Max. power calculated" column below. Calculate the "Error \%" value using the formula shown in the 
third column. The max value is the maximum power generated by the solar panel. The values calculated from the measured currents and voltages might be lower than the specification of the panel ${ }^{8}$. One of the reasons is that the white LEDs on the fixture emit an optical spectral distribution that is different from that of sunlight as shown in Figure 4.

\begin{tabular}{|c|c|cc|}
\hline Max. power calculated & Datasheet value & Error \% \\
\hline \hline & $2.0[\mathrm{~W}](1 \mathrm{~W}$ & $\frac{2.0-\text { Max.Power Calculated }}{2.0} \times 100=$ & {$[\%]$} \\
\hline
\end{tabular}

\section{Spectral distribution comparison:}

The reference solar spectral irradiance for evaluating photovoltaic performance is developed by the photovoltaic industry with the American Society for Testing and Materials (ASTM) and government R\&D laboratories ${ }^{12}$. The irradiance is presented in the ASTM G173 document. Figure 4 shows the two spectral irradiance distributions: solar (black dotted line) and a white LED (blue solid line) ${ }^{13}$. As seen in the figure, the solar irradiance has a much wider distribution up to the infrared range, whereas the white LED spectral distribution goes up to $790 \mathrm{~nm}$ with only two peaks at the wavelengths of $430 \mathrm{~nm}$ and $600 \mathrm{~nm}$. The white LED does not produce much of the solar spectral irradiance.

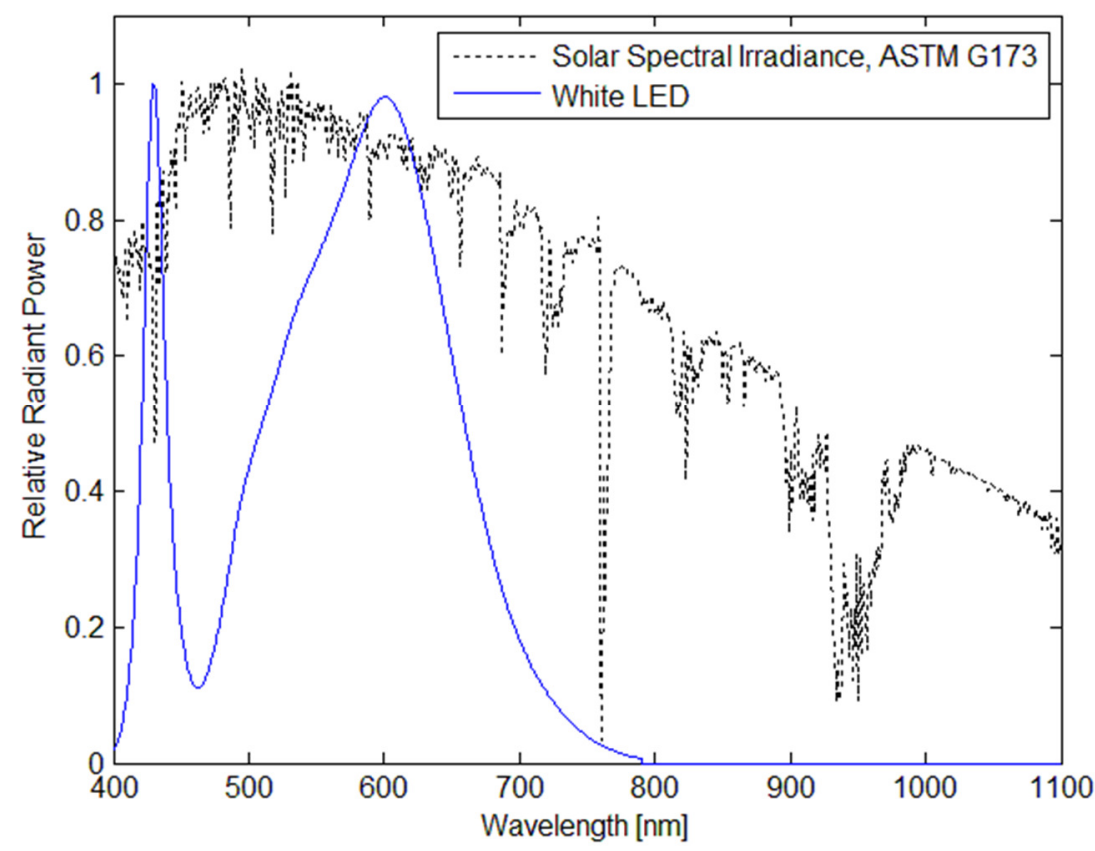

Figure 4: Solar and white LED spectral distribution

\section{Student Feedback and Assessment Method}

The following survey questions were given to students and the results are shown below each question. A five-point Likert scale was used (1: Strongly Disagree, 2: Disagree, 3: Neutral, 4: Agree, 5: Strongly Agree). Students were asked to assess how well the outcomes were met. The total number of students who completed the survey was 21 . 
Learning Outcomes: By the end of the lab, students should be able to:

1) Understand that a solar panel can produce an output voltage and current (or energy) when facing a light source.

\begin{tabular}{|c|c|c|c|c|c|c|}
\hline 1: S. D. & 2: D & 3: N & 4: A & 5: S. A. & Avg. & Avg.\% \\
\hline 0 & 0 & 0 & 2 & 19 & 4.90 & 98.1 \\
\hline
\end{tabular}

2) Measure the open circuit voltage of solar panel (by leaving the output terminals of solar panel disconnected) and the short circuit current (by connecting the terminals together).

\begin{tabular}{|c|c|c|c|c|c|c|}
\hline 1: S. D. & 2: D & 3: N & 4: A & 5: S. A. & Avg. & Avg.\% \\
\hline \hline 0 & 0 & 0 & 3 & 18 & 4.86 & 97.1 \\
\hline
\end{tabular}

3) Comprehend that a solar power controller (battery charger) can deliver power to a battery (storage element) and can monitor battery charge status (e.g. Green: nearly full, Yellow: half full, Red: low/empty).

\begin{tabular}{|c|c|c|c|c|c|c|}
\hline 1: S. D. & 2: D & 3: N & 4: A & 5: S. A. & Avg. & Avg.\% \\
\hline \hline 0 & 0 & 0 & 4 & 17 & 4.81 & 96.2 \\
\hline
\end{tabular}

4) Understand that a battery can store energy harvested by a solar panel and that energy stored in the battery can be used to turn on a lamp (load) even though a light source is not available.

\begin{tabular}{|c|c|c|c|c|c|c|}
\hline 1: S. D. & 2: D & 3: $\mathrm{N}$ & 4: A & 5: S. A. & Avg. & Avg.\% \\
\hline \hline 0 & 0 & 0 & 3 & 18 & 4.86 & 97.1 \\
\hline
\end{tabular}

5) Measure solar panel currents and voltages while varying a load attached to the output of the solar panel and calculate the maximum power that a solar panel can generate from the measured currents and voltages.

\begin{tabular}{|c|c|c|c|c|c|c|}
\hline 1: S. D. & 2: D & 3: N & 4: A & 5: S. A. & Avg. & Avg.\% \\
\hline \hline 0 & 0 & 0 & 1 & 20 & 4.95 & 99.0 \\
\hline
\end{tabular}

Overall lab experience:

6) The lab contributed to the understanding of the concept about solar power systems.

\begin{tabular}{|c|c|c|c|c|c|c|}
\hline 1: S. D. & 2: D & 3: N & 4: A & 5: S. A. & Avg. & Avg.\% \\
\hline \hline 0 & 0 & 0 & 6 & 15 & 4.71 & 94.3 \\
\hline
\end{tabular}

7) Students gained a valuable basic knowledge about solar power systems from this lab experience with the demonstration unit. (e.g., how to obtain environment-friendly energy from sunlight through solar panels, to store energy harvested from sunlight)

\begin{tabular}{|c|c|c|c|c|c|c|}
\hline 1: S. D. & 2: D & 3: N & 4: A & 5: S. A. & Avg. & Avg.\% \\
\hline 0 & 0 & 0 & 4 & 17 & 4.81 & 96.2 \\
\hline
\end{tabular}

Based on the tables above, the students strongly indicated that the learning outcomes were achieved. In particular, Questions 6) \& 7) summarize the students' overall learning and the results show that the students appreciated the lab and felt that it was an excellent learning exercise. 


\section{Conclusions and Future Work}

The approach was taken to integrate students' prior knowledge and experiences with basic electric circuits. The step-by-step procedures were used to conduct the experiments effectively and to improve students' understanding.

The lab experiment presented is based on the solar power demonstration unit. The unit is made from standard test and measurement equipment and hardware available at a hardware store. This paper includes lab experiments materials in detail, including a complete wiring diagram, a bill of materials, photos, and measurement results. This unit is portable and, therefore, can be utilized in a lab or class and tested with true sunlight in an outdoor setting.

Based on the survey results in Section 6, students appreciated the lab experiment. It was indicated that the lab experiment presented in this paper helped students understand the concept and gain knowledge about solar power systems.

Future work will involve adding a solar simulator, which can emit spectral irradiance that better matches that of sunlight to harvest more power.

\section{References}

1. PV EDUCATION ORG, http://pveducation.org/pvedrom/introduction/solar-energy

2. Ignacio B. Osorno, "Applied Modeling of Solar Cells," Proc. 2011 ASEE Annual Conference and Exposition, 2011

3. Herbert L. Hess, “A Simple Laboratory Exercise Introducing Photovoltaics,” Proc. 2013 ASEE Annual Conference and Exposition, 2013

4. Faruk Yildiz, Min Jae Suh, and et al., "Design and Development of a Grid-Tied Solar Photovoltaic Training Infrasturcture," Proc. 2016 ASEE Annual Conference and Exposition, 2016

5. Elena V. Brewer and Anthony P. Dalessio, "Effective Low-Budget Approach to Teaching Photovoltaic Systems to Electrical Engineering Technology Students at Community Colleges," Proc. 2011 ASEE Annual Conference and Exposition, 2012

6. Marktech Optoelectronics, LED MCPCB XBD Warm White (Digikey Part Number 1125-1164-ND), www.marktechopto.com/pdf/products/datasheet/XBD_WHITE.pdf

7. CREE, XBD Warm White LED datasheet, www.cree.com/ /media/Files/Cree/LED-Components-andModules/XLamp/Data-and-Binning/XLampXBD.pdf

8. Parallax, Solar Panel6V@1W datasheet, www.mouser.com/ds/2/321/parallax_750-00030-solar-panel-6vspecifications-552010.pdf

9. Amprobe, SOLAR-100 Solar Power Meter, www.amprobe.com

10. Occupational Safety and Health Administration, Eye Protection against Radiant Energy during Welding and Cutting in Shipyard Employment, www.osha.gov

11. Morningstar, SunSaver-10, SS-10-12V datasheet, http://www.morningstarcorp.com/wpcontent/uploads/2014/02/SS3.IOM_.Operators_Manual.01.EN_.pdf

12. Reference Solar Spectral Irradiance: ASTM G-173, Global Tilt, http://rredc.nrel.gov/solar/spectra/am1.5/

13. OSRAM Opto Semiconductors, Platinum Dragon White LCW W5SN-KYLY-4J8K-Z (Digikey Part Number 475-2626-1-ND), http:/www.osram-os.com/osram_os/en/products/product-catalog/led-light-emittingdiodes/platinum-dragon/lcw-w5sn/index.jsp 